\title{
ANN Robot Energy Modeling
}

\author{
Fernando Rios-Gutierrez, Adel El-Shahat, Mudasser Wahab \\ (Department of Electrical Engineering Georgia Southern University Statesboro, Georgia 30458)
}

\begin{abstract}
This paper proposes energy modeling for robot based on real measurements data. First, the paper proposes six preliminary ANN Models on both carpet and hard floor. These models' Inputs: Theoretical Time, Theoretical Velocity and Output: The Current; then with Inputs: Theoretical Time, Theoretical Velocity and Output: The Current, The Voltage; and finally with Inputs: Time, Real Linear Velocity, Rotational Velocity and Output: The Current, The Voltage. Second, a global ANN model with time and speed as inputs and current, voltage, linear speed, rotational speed on carpet, along with current, voltage, linear speed, rotational speed on hard floor. This general model is presented in the form of Simulink model after care selection of number in neurons in hidden layer. This model has the capability to predict and simulate the robot energy characteristics under different conditions. This real data measurements on both hard floor and carpet are presented to be used as training data for Neural Network. All the ANN models are checked in the form of minimum error, accuracy, good regression constants and comparisons between real and predicted data. ANN with feed forward backpropagation technique is used to implement the models. It is adopted to make benefits from its ability of interpolation. ANN models with Back - Propagation (BP) technique is created with suitable numbers of layers and neurons. The last model will be used with the aid of Genetic Algorithm to improve and optimize the energy efficiency of robots.
\end{abstract}

Keywords: Energy, Modeling, Simulink, Artificial Neural Network, Estimation.

\section{Introduction}

It is a very important issue to model Mobile robots in order to make complete performance analysis and optimize this performance. The purpose of proper modeling and optimization is to solve the problem of limited amount of robots energy. Many important contributions from other researchers related to robots modeling are reviewed with advantages and drawbacks before starting this work [1], [2], [3], [4], [5]. Robots design, control, and implementation work are done using ANN like [6], [7]. Due to the enormous development in the field of robotics, robots and especially autonomous mobile robots have found their use in a lot of applications. These applications include search and rescue, security, rehabilitation, cleaning and delivery. Autonomous mobile robots most of the time rely on batteries as their energy source and batteries have very limited energy capacity. This finite amount of energy can make the robot work only for a limited time and this is why the use of these robots in complicated missions is not feasible. Although these robots could be refueled while they are operating and their time of operation can be increased; the cost of replacement of their energy source is too high to be realistic. So, our global ANN model will become a very important one especially for optimization analysis. Especially, this model accomplishes all important performance characteristics and based on real experimental measurements.

\section{Experimental Data}

The experimental data are drawn from the robot and associated measurements devices which used in [1] for the same authors as shown in the following samples figures. The used robot was built at the first author's laboratory by his previous students as shown in Fig. 1 to measure required data.
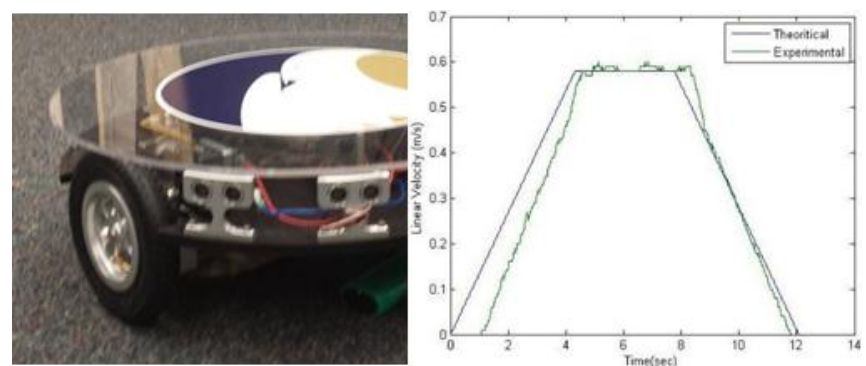

Fig. 1 The used Robot for measuring the training data [1] 
The current is measured by an ACS712 current sensor as shown in Fig. 2. Current data is fed into an Arduino Mega 2560 during the robot's motion. The sampling time was set at $26 \mathrm{~ms}$ because our robot's maximum speed is $0.58 \mathrm{~m} / \mathrm{s}$

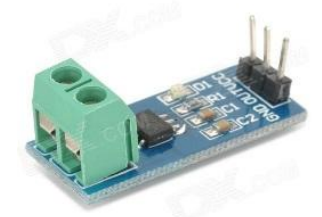

Fig. 2. ACS712 current sensor module [1]

This data introduced in the following figures and more is used as training data for ANN models.

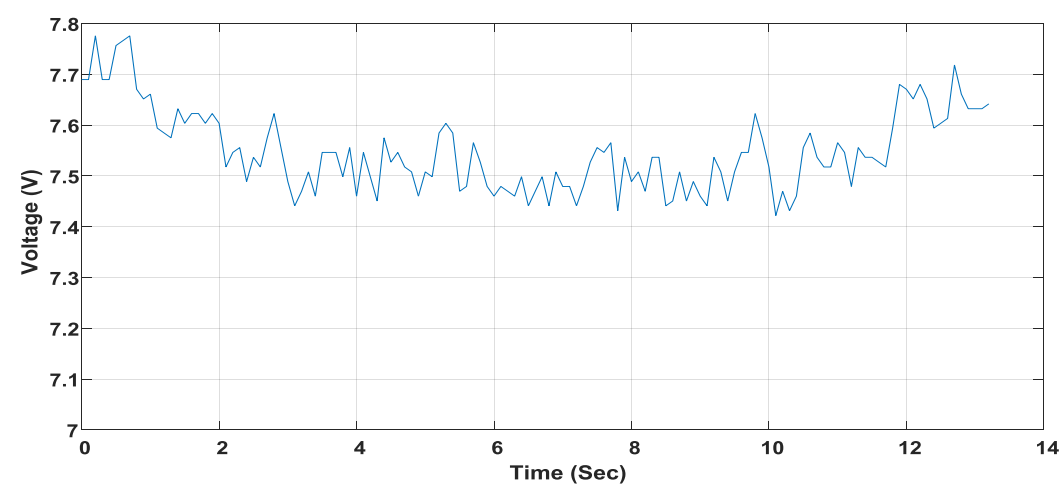

Fig. 3 Voltage and Time Relation on Carpet.

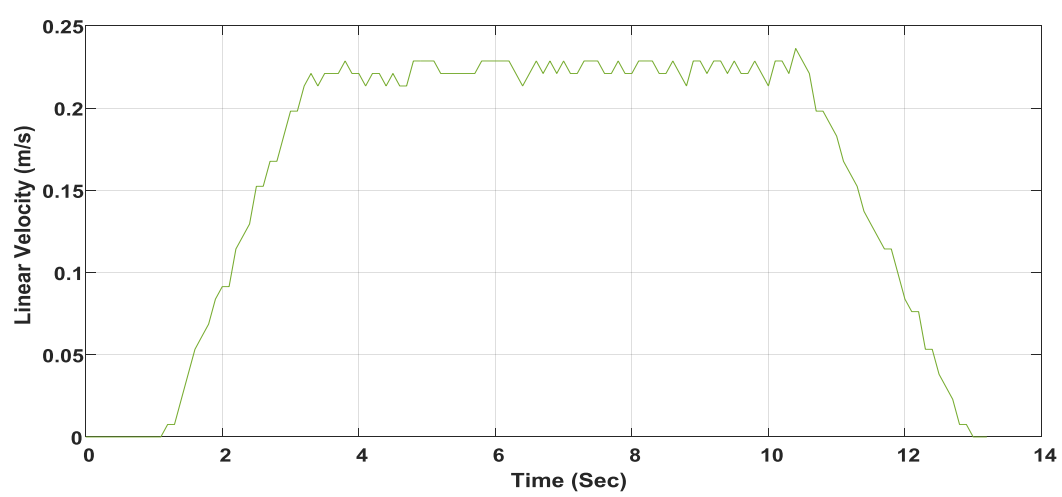

Fig. 4 Linear Velocity and Time Relation on Carpet.

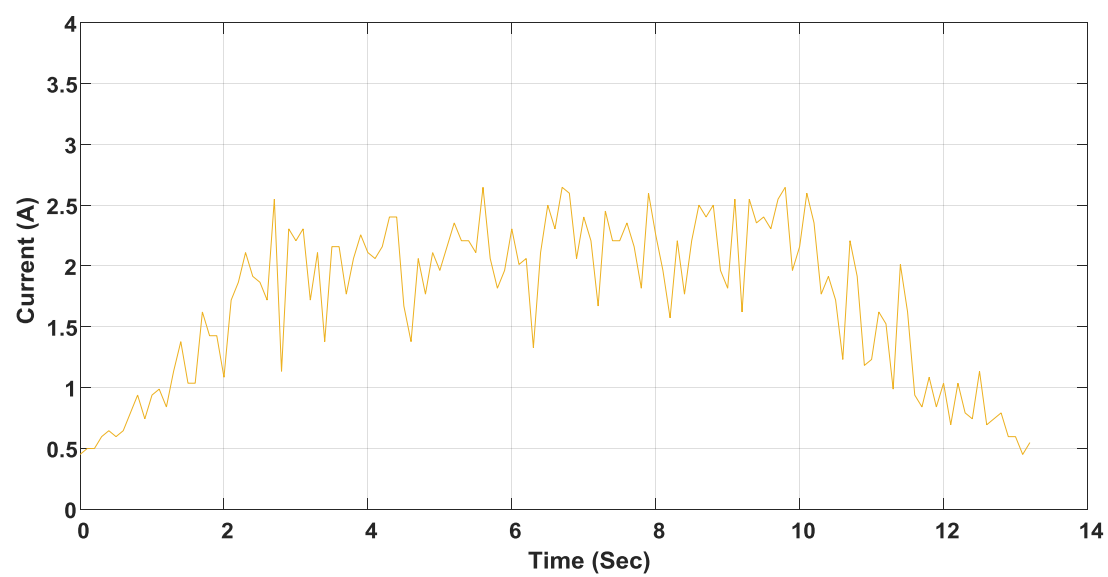

Fig. 5 Current and Time Relation on Carpet. 


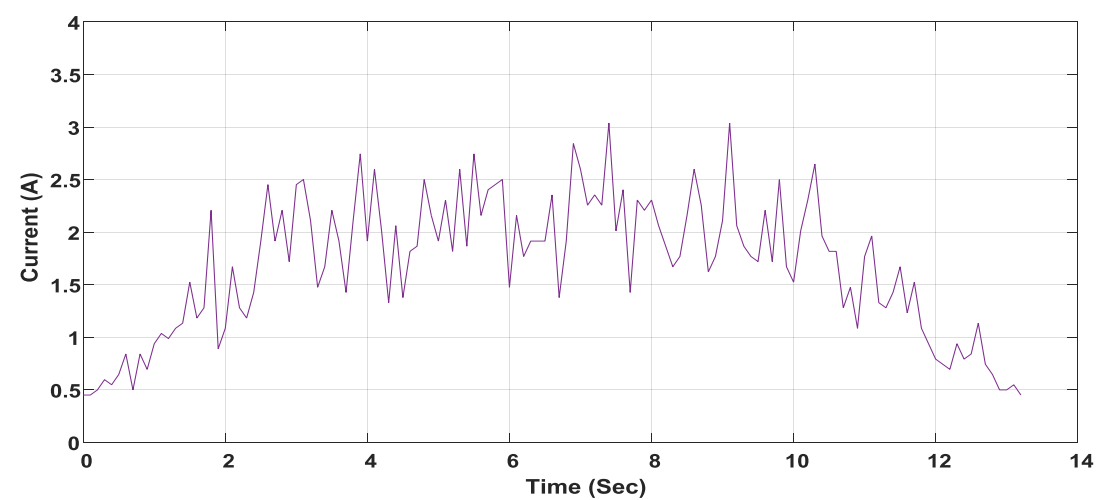

Fig. 6 Current and Time Relation on Hard-Floor.

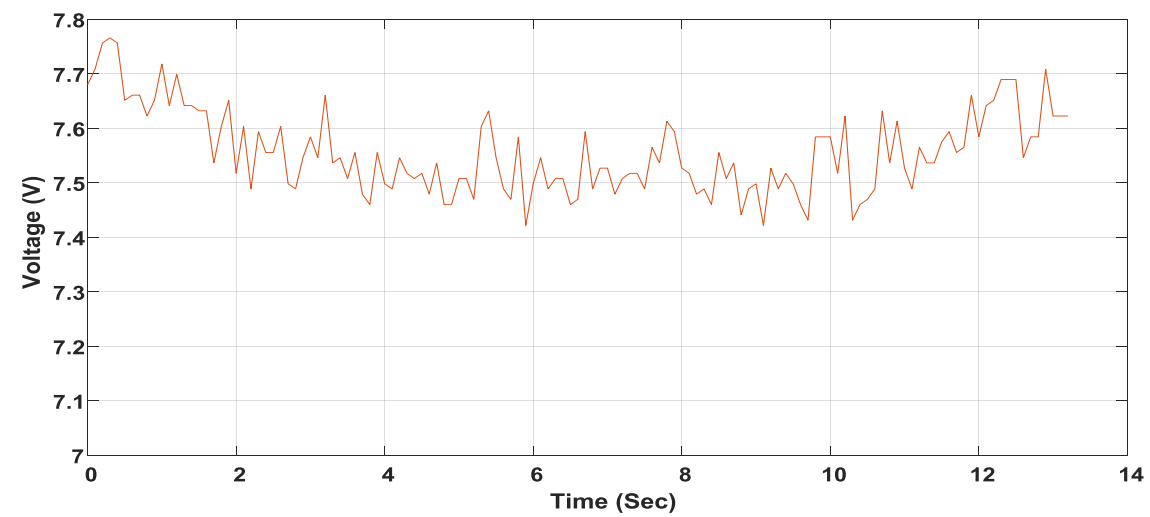

Fig. 7 Voltage and Time Relation on Hard-Floor.

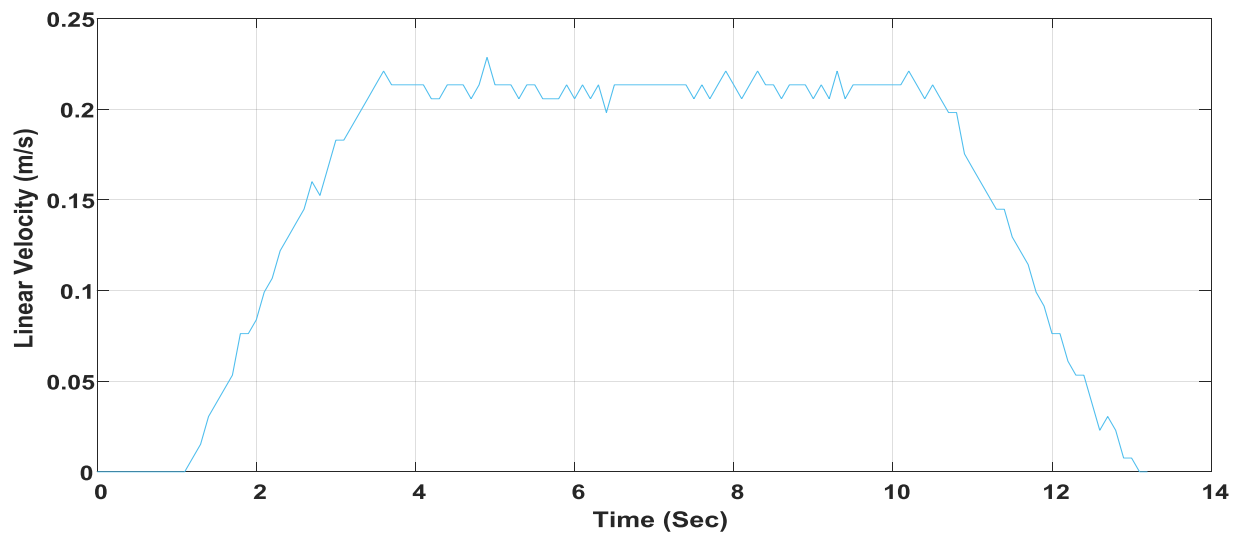

Fig. 8 Linear Velocity and Time Relation on Hard-Floor.

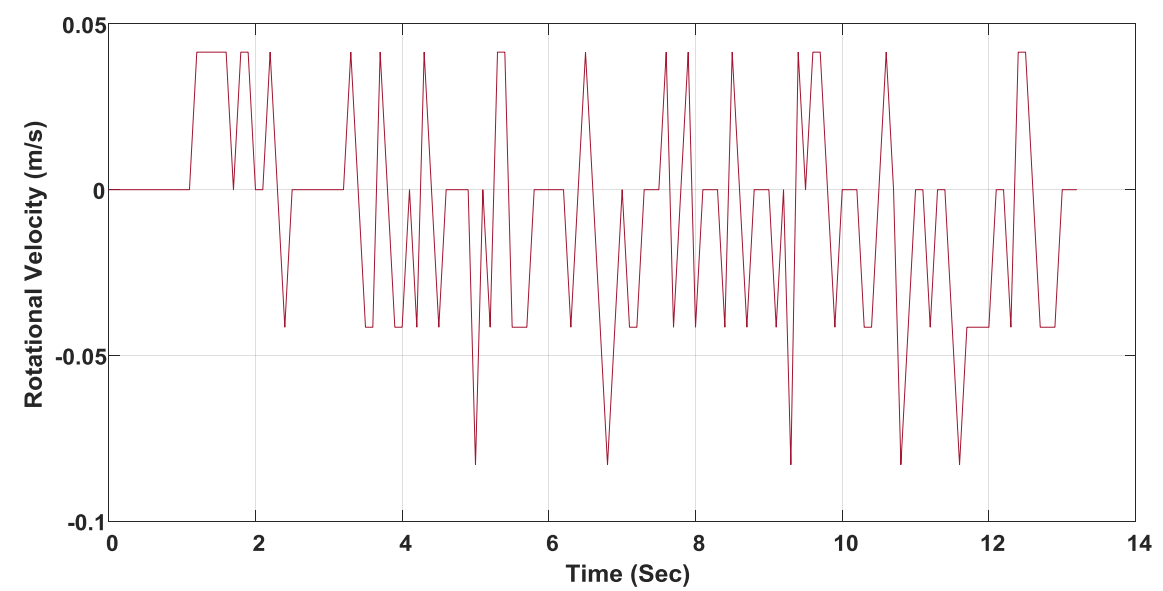

Fig. 9 Rotational Velocity and Time Relation on Carpet. 


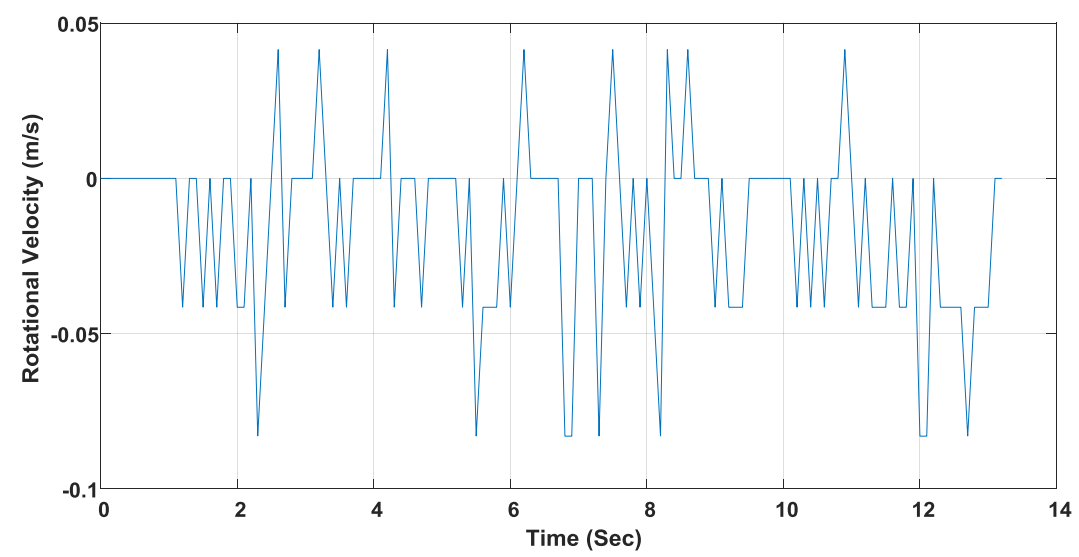

Fig. 10 Rotational Velocity and Time Relation on Hard-Floor.

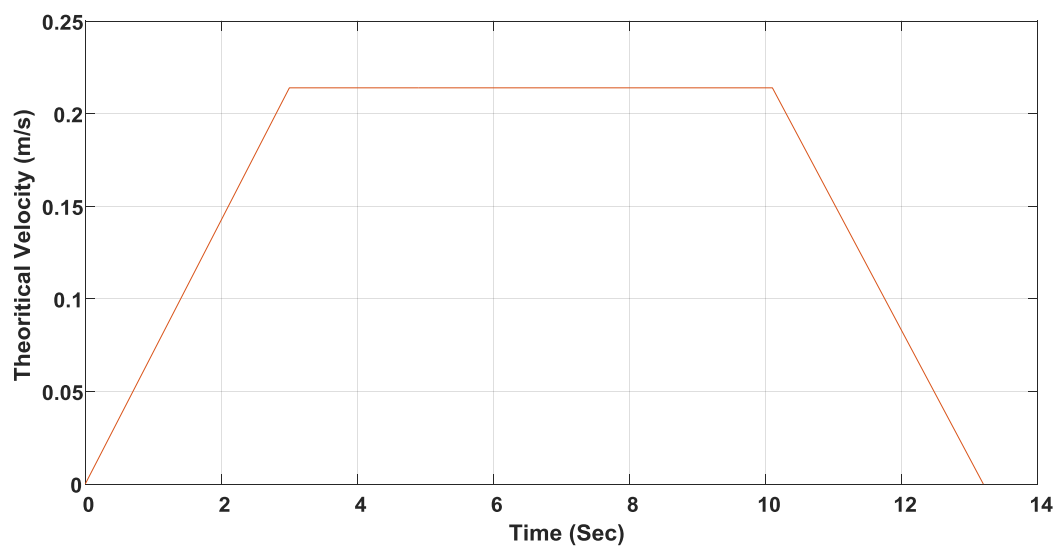

Fig. 11 Theoretical Velocity and Time Relation.

\section{Ann Models}

Artificial Neural Network with feed forward back-propagation technique is used to implement the various ANN models [8]-[11]. All the models consist of one hidden contains log-sigmoid function and other is output layer contains pure-line function. Carpet Model 1: Inputs: Time, Velocity, Output: Current; with 7 neurons and 1 neuron. $(\mathrm{R}=0.99105)$. 2nd Carpet Model: The same i/ps as 1st model, O/ps: Current, Voltage; 8 neurons and 2 neurons. $(\mathrm{R}=0.9766)$. 3rd Carpet Model: I/ps: Time, Linear Velocity, Rotational Velocity; o/ps: Current, Voltage; 7 neurons and 2 neurons. $(\mathrm{R}=0.99511)$. Hard floor: Model 1: I/ps: Time, Velocity; O/p: Current; 6 neurons, 1 neuron. ( $\mathrm{R}=0.98189)$. Model 2: same i/ps; O/p: Current, Voltage; 11 neurons, 2 neurons. $(\mathrm{R}=0.98188)$. Model 3: I/ps: Time, Linear Velocity, Rotational Velocity, O/ps: Current, Voltage, 7 neurons, 2 neurons. $(\mathrm{R}=0.97472)$.

\section{A. Carpet Models}

\section{ANN Model 1 for the carpet:}

Inputs: Theoretical Time, and Theoretical Velocity

Output: The Current

Neural Network consists of two layers one hidden contains log-sigmoid function with seven neurons and the other is the output layer contains pure-line function with one neuron.

The normalized inputs eq.n are:

Time $_{\mathrm{n}}=($ Time -1.5000$) /(0.9092)$

Velocity $_{\mathrm{n}}=($ Velocity -0.1070$) /(0.0649)$

Equation (1) presents the normalized input for the power and the following equations lead to the required derived equation.

$\mathrm{n}$ : Subscript denotes normalized parameters

Ei: Sum of input with input weight and input bias for each node in hidden layer in neural network

Fi: Output from each node in hidden layer to output layer according to transfer function here is logsig

$\mathrm{E} 1=-0.0206$ Time $_{\mathrm{n}}+6.2084$ Velocity $_{\mathrm{n}}+0.8792$ 
$\mathrm{F} 1=1 /(1+\exp (-\mathrm{E} 1))$

E2 $=-41.9445$ Time $_{n}-36.2368$ Velocity $_{n}+107.7541$

$\mathrm{F} 2=1 /(1+\exp (-\mathrm{E} 2))$

$\mathrm{E} 3=1.8870 \quad$ Time $_{\mathrm{n}}+4.3406$ Velocity $_{\mathrm{n}}+1.3116$

$\mathrm{F} 3=1 /(1+\exp (-\mathrm{E} 3))$

$\mathrm{E} 4=12.2653$ Time $_{\mathrm{n}}+7.9388$ Velocity $_{\mathrm{n}}-2.9239$

$\mathrm{F} 4=1 /(1+\exp (-\mathrm{E} 4))$

E5 $=-51.7383 \quad$ Time $_{n}-58.0546$ Velocity $_{n}+71.4314$

$\mathrm{F} 5=1 /(1+\exp (-\mathrm{E} 5))$

E6 $=-63.1920 \quad$ Time $_{n}-68.1760$ Velocity $_{n}+180.9475$

$\mathrm{F} 6=1 /(1+\exp (-\mathrm{E} 6))$

E7 $=-3.7685 \quad$ Time $_{n}-2.7997$ Velocity $_{n}-1.7873$

$\mathrm{F} 7=1 /(1+\exp (-\mathrm{E} 7))$

The normalized current relation from ANN:

$I_{n}=-171.7834$ F1 - 114.3126 F2 + 318.7558 F3 + 4.4619 F4 - 1.4824 F5 + 113.6865 F6 + 150.6382 F7 -149.7478

(3)

The un- normalized output (Current) on Carpet $\mathrm{I}=0.5977 * \mathrm{I}_{\mathrm{n}}+1.2486$

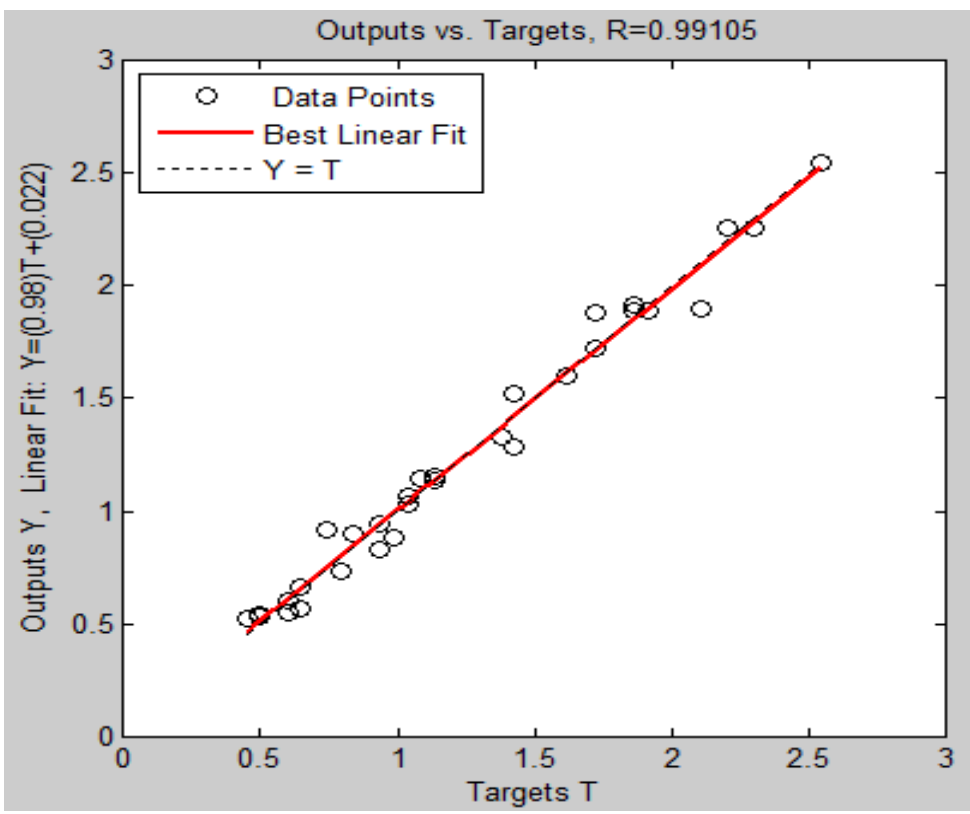

Fig. 12 Output VS Target for ANN Model testing data

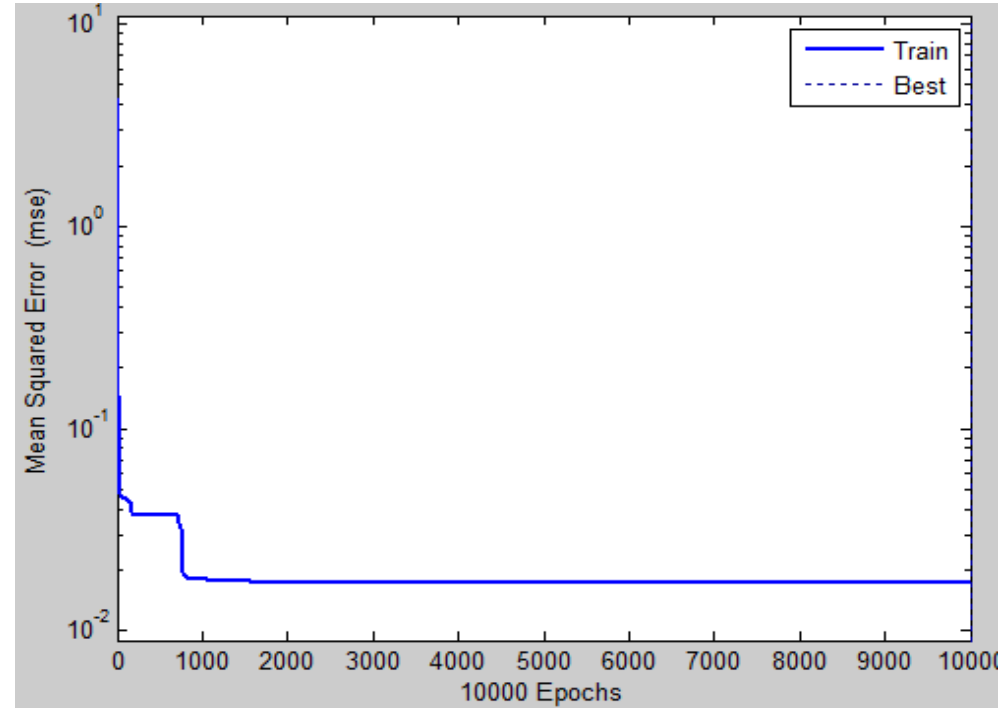

Fig. 13 Performance for the Model 


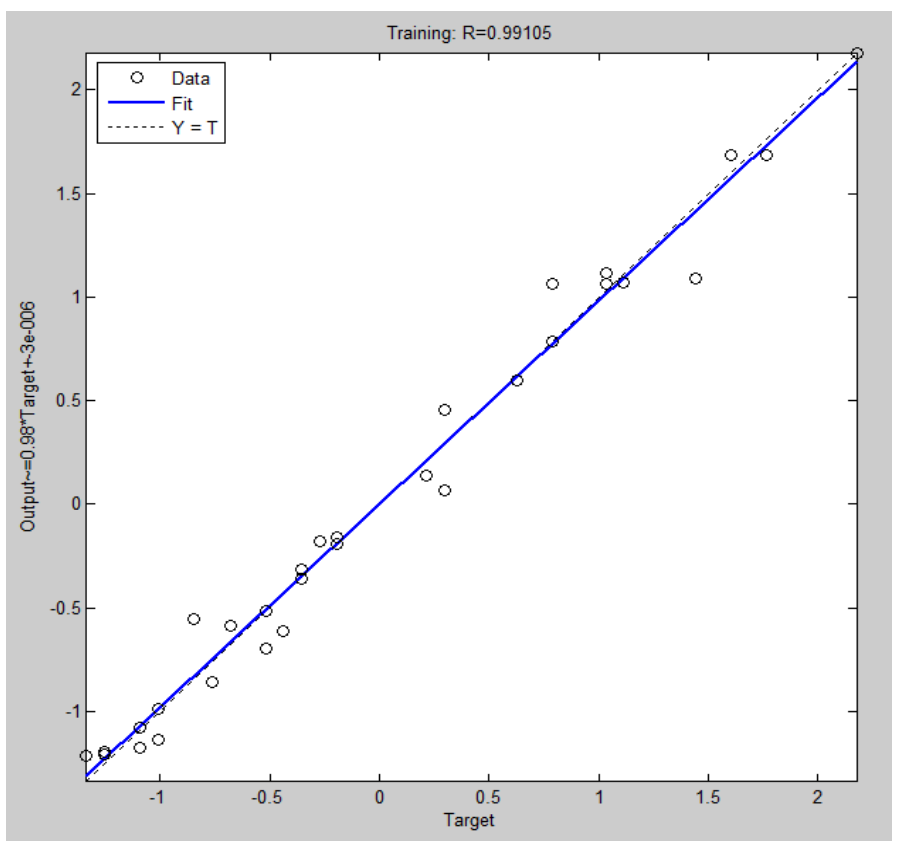

Fig. 14 Regression for ANN Model

\section{$2^{\text {nd }}$ ANN Model for the carpet:}

Inputs: Theoretical Time, and Theoretical Velocity

Output: The Current, The Voltage

Neural Network consists of two layers one hidden contains log-sigmoid function with eight neurons and the other is the output layer contains pure-line function with two neurons.

Equation (1) presents the normalized input for the power and the following equations lead to the required derived equation.

$$
\begin{aligned}
& \mathrm{E} 1=-30.3556 \text { Time }_{\mathrm{n}}-34.0484 \text { Velocity }_{\mathrm{n}}+88.0686 \\
& \mathrm{~F} 1=1 /(1+\exp (-\mathrm{E} 1)) \\
& \mathrm{E} 2=112.9999 \text { Time }_{\mathrm{n}}+110.6328 \text { Velocity }_{\mathrm{n}}-145.2920 \\
& \mathrm{~F} 2=1 /(1+\exp (-\mathrm{E} 2)) \\
& \mathrm{E} 3=99.6837 \text { Time }_{\mathrm{n}}+104.0222 \text { Velocity }_{\mathrm{n}}-287.2837 \\
& \mathrm{~F} 3=1 /(1+\exp (-\mathrm{E} 3)) \\
& \mathrm{E} 4=110.4102 \quad \text { Time }_{\mathrm{n}}+103.6221 \text { Velocity }_{\mathrm{n}}+45.5007 \\
& \mathrm{~F} 4=1 /(1+\exp (-\mathrm{E} 4)) \\
& \mathrm{E} 5=103.9192 \quad \text { Time }_{\mathrm{n}}+97.3830 \text { Velocity }_{\mathrm{n}}-250.3730 \\
& \mathrm{~F} 5=1 /(1+\exp (-\mathrm{E} 5)) \\
& \text { E6 }=9.4533 \text { Time }_{\mathrm{n}}+2.8637 \text { Velocity }_{\mathrm{n}}+14.2774 \\
& \mathrm{~F} 6=1 /(1+\exp (-\mathrm{E} 6)) \\
& \text { E7 }=-90.8838 \quad \text { Time }_{n}-84.2455 \text { Velocity }_{n}-269.1573 \\
& \mathrm{~F} 7=1 /(1+\exp (-\mathrm{E} 7)) \\
& \mathrm{E} 8=0.4986 \quad \text { Time }_{\mathrm{n}}+2.5868 \text { Velocity }_{\mathrm{n}}+4.4950 \\
& \mathrm{~F} 8=1 /(1+\exp (-\mathrm{E} 8)) \\
& \text { The normalized current relation from ANN: } \\
& \mathrm{I}_{\mathrm{n}}=1.0 \mathrm{e}+004 *(-1.8034 \mathrm{~F} 1+0.0001 \mathrm{~F} 2-1.7231 \mathrm{~F} 3+0.00004 \mathrm{~F} 4-0.0801 \mathrm{~F} 5-0.0001 \mathrm{~F} 6+0.0001 \mathrm{~F} 7
\end{aligned}
$$

The un- normalized outputs (Current \& Voltage) for carpet $\mathrm{I}=0.5977 * \mathrm{I}_{\mathrm{n}}+1.2486$

$$
\mathrm{V}=0.0808 * \mathrm{~V}_{\mathrm{n}}+7.6220
$$




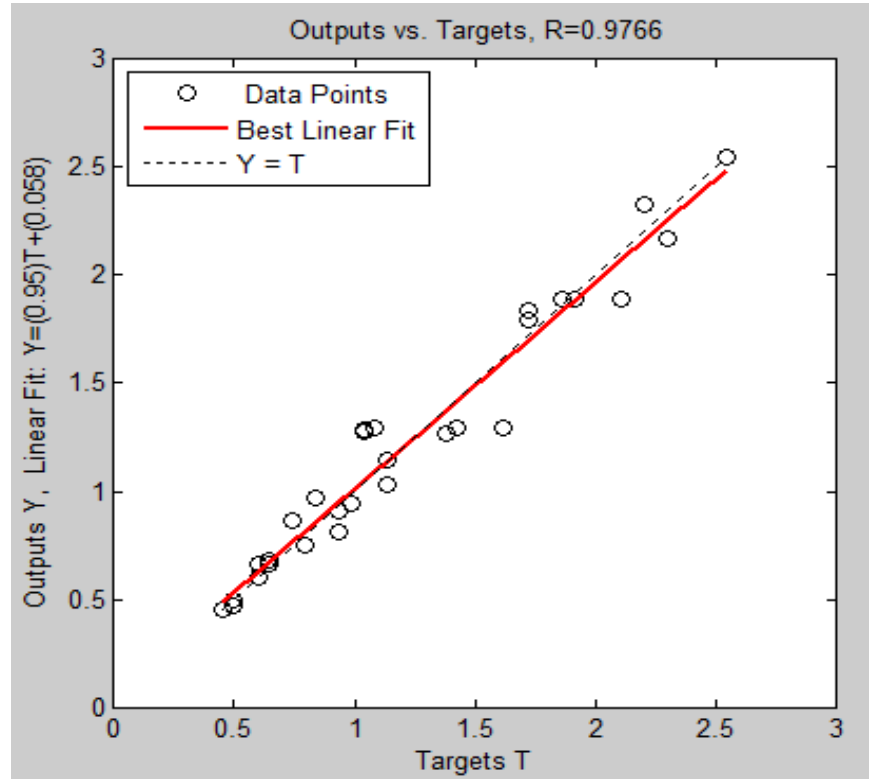

Fig. 15 Output VS Target for ANN Model testing data

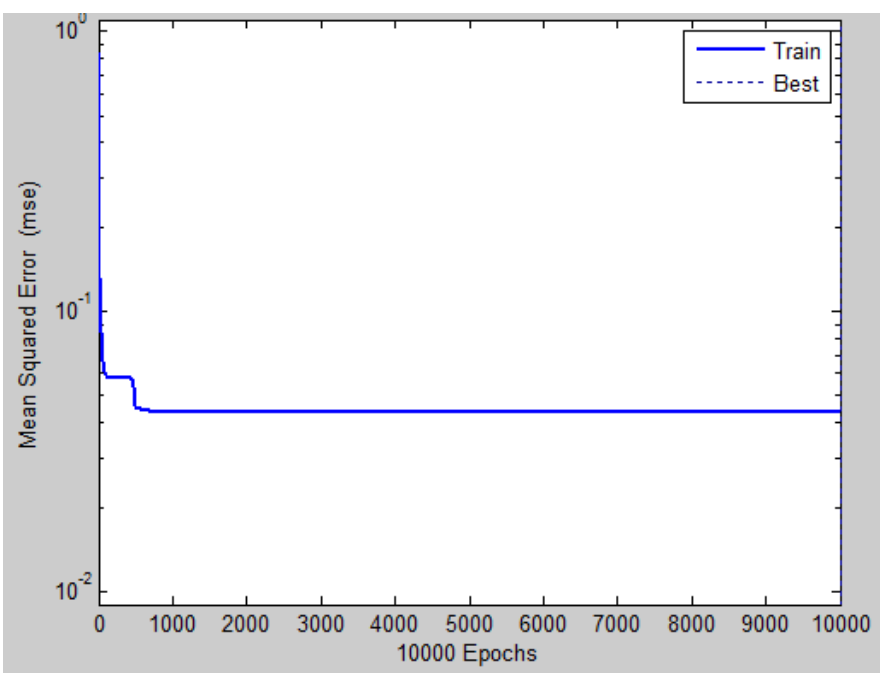

Fig. 16 Performance for the Model

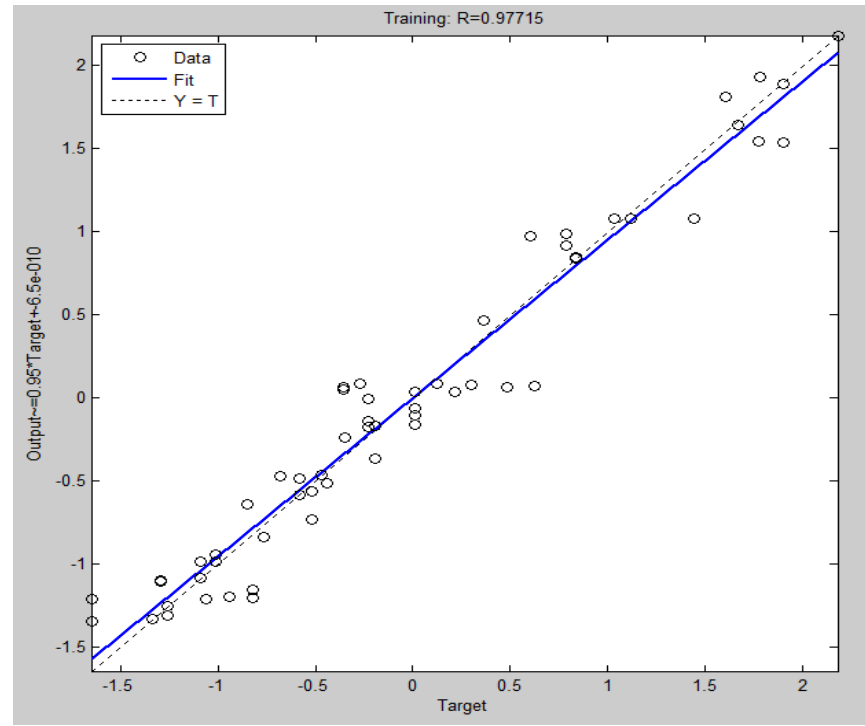

Fig. 17 Regression for ANN Model 


\section{$3^{\text {rd }}$ ANN Model for the carpet:}

Inputs: Time, Linear Velocity, and Rotational Velocity

Output: The Current, The Voltage

Neural Network consists of two layers one hidden contains log-sigmoid function with seven neurons and the other is the output layer contains pure-line function with two neurons.

The normalized inputs eq.n are:

Time $_{\mathrm{n}}=($ Time -1.5000$) /(0.9092)$

Linear_Velocity $\mathrm{n}_{\mathrm{n}}($ Linear_Velocity -0.0617$) /(0.0681)$

Rotational_Velocity $=($ Rotational_Velocity - 0.0094) / (0.0206)

Equation (10) presents the normalized input for the power and the following equations lead to the required derived equation.
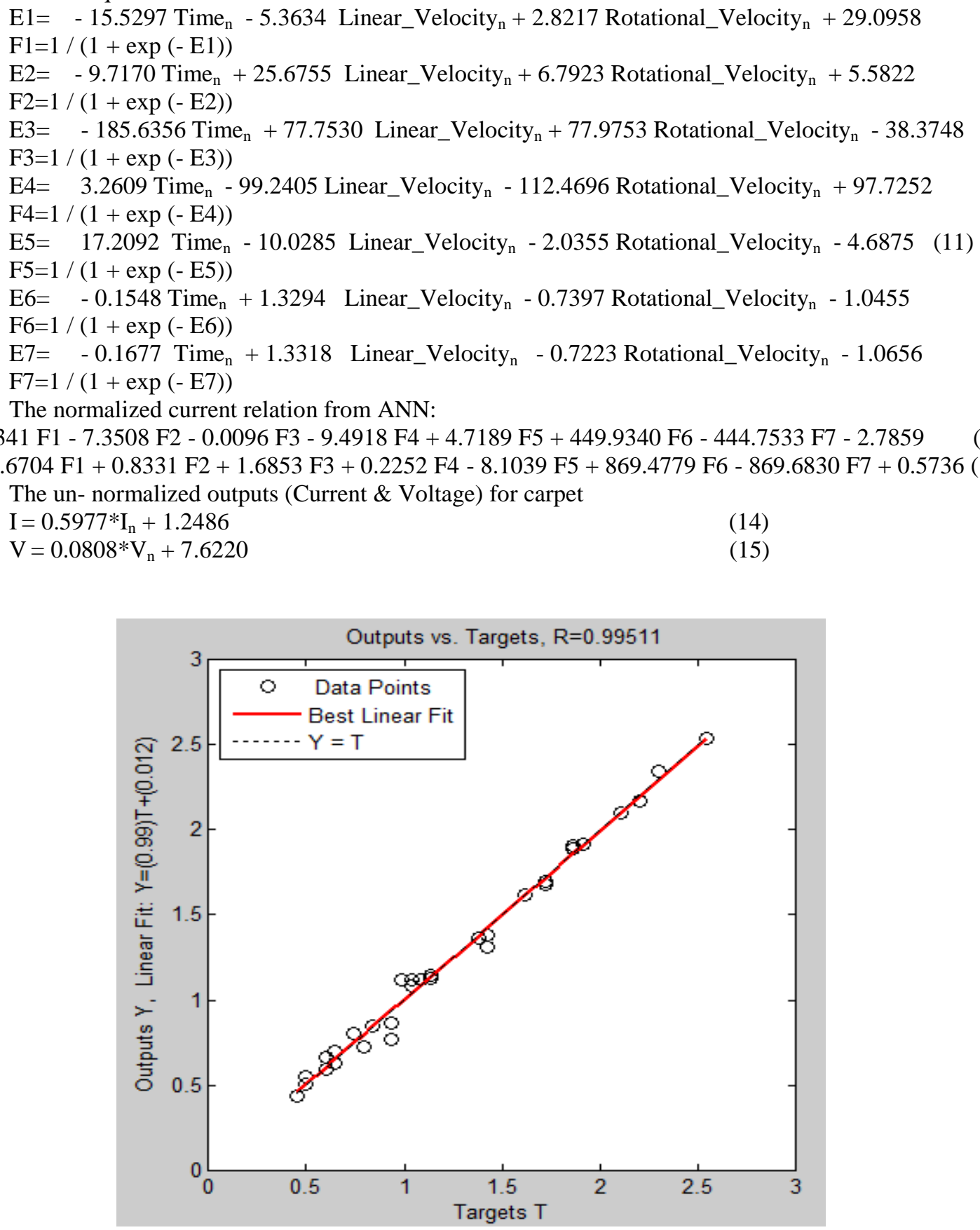

Fig. 18 Output VS Target for ANN Model testing data 


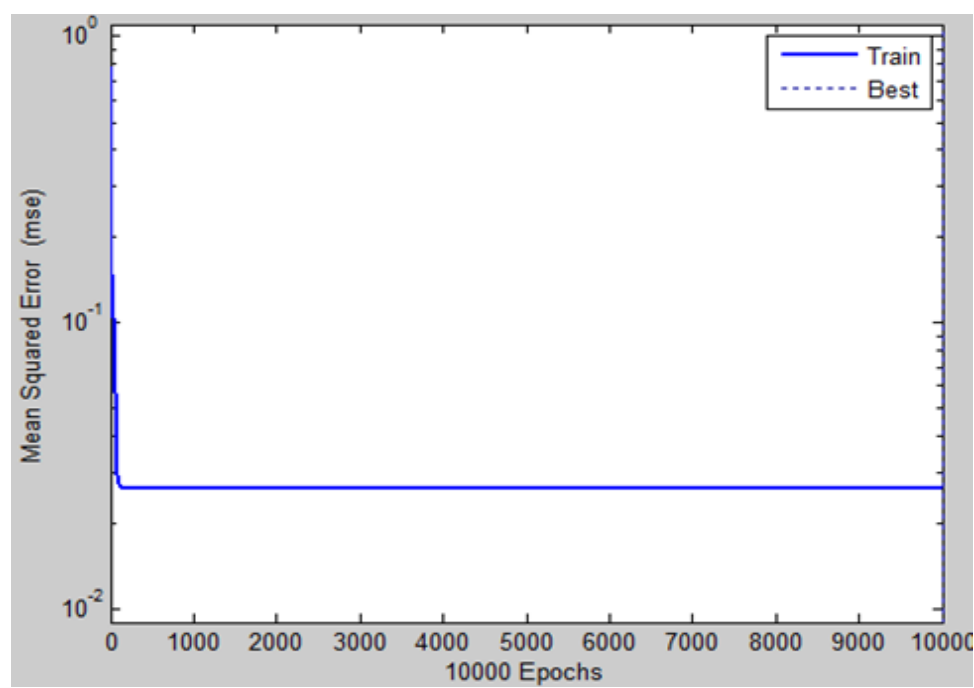

Fig. 19 Performance for the Model

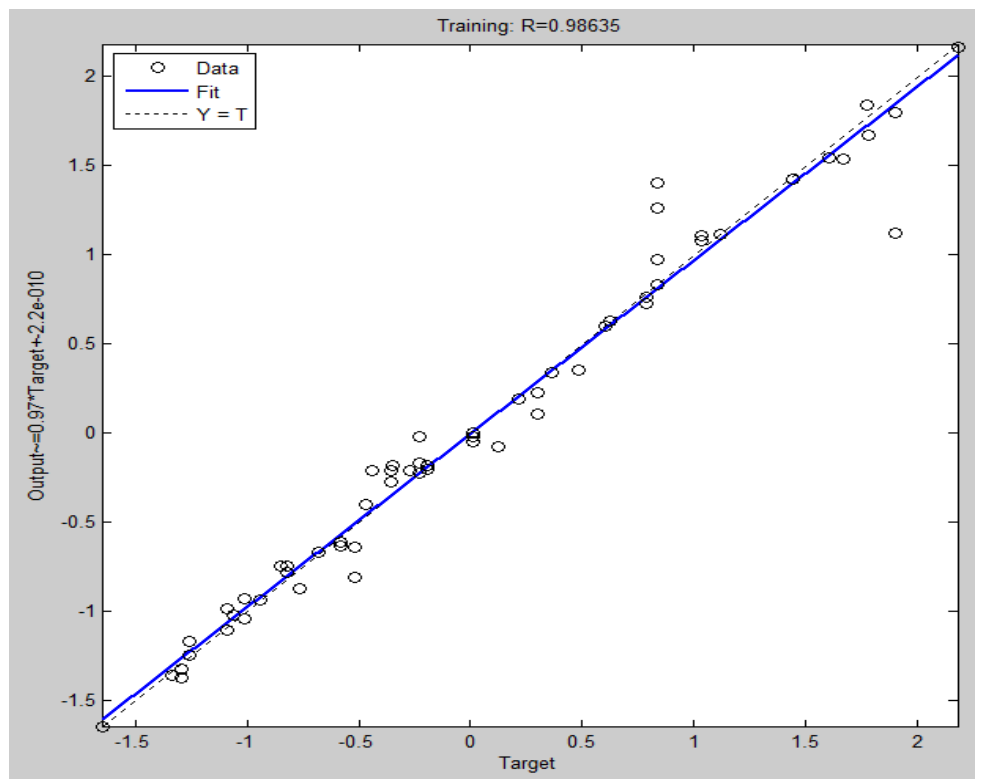

Fig. 20 Regression for ANN Model

\section{B. Hard floor Models}

ANN Model 1 for the hard floor:

Inputs: Theoretical Time, and Theoretical Velocity

Output: The Current

Neural Network consists of two layers one hidden contains log-sigmoid function with six neurons and the other is the output layer contains pure-line function with one neuron.

The normalized inputs eq.n are:

Time $_{n}=($ Time -1.5000$) /(0.9092)$

Velocity $_{\mathrm{n}}=($ Velocity -0.1070$) /(0.0649)$

Equation (16) presents the normalized input for the power and the following equations lead to the required derived equation.

$\mathrm{N}$ : Subscript denotes normalized parameters

Ei: Sum of input with input weight and input bias for each node in hidden layer in neural network

Fi: Output from each node in hidden layer to output layer according to transfer function here is logsig

$\mathrm{E} 1=3.5120$ Time $_{\mathrm{n}}-2.1097$ Velocity $_{\mathrm{n}}-5.2000$

$\mathrm{F} 1=1 /(1+\exp (-\mathrm{E} 1))$

$\mathrm{E} 2=-4.5842$ Time $_{\mathrm{n}}-1.4050$ Velocity $_{\mathrm{n}}+6.5328$

$\mathrm{F} 2=1 /(1+\exp (-\mathrm{E} 2))$ 
E3 $=5.1731$ Time $_{n}+0.7477$ Velocity $_{n}-6.4648$

$\mathrm{F} 3=1 /(1+\exp (-\mathrm{E} 3))$

$\mathrm{E} 4=35.3574$ Time $_{\mathrm{n}}+38.8344$ Velocity $_{\mathrm{n}}-32.6172$

$\mathrm{F} 4=1 /(1+\exp (-\mathrm{E} 4))$

$\mathrm{E} 5=180.2645$ Time $_{\mathrm{n}}+181.4834$ Velocity $_{\mathrm{n}}-21.6003$

$\mathrm{F} 5=1 /(1+\exp (-\mathrm{E} 5))$

E6= 100.4598 Time $_{n}+94.6200$ Velocity $_{n}-85.7998$

$\mathrm{F} 6=1 /(1+\exp (-\mathrm{E} 6))$

The normalized current relation from ANN:

$\mathrm{I}_{\mathrm{n}}=1.0 \mathrm{e}+003 *(0.3371 \mathrm{~F} 1-1.3742 \mathrm{~F} 2-1.3922 \mathrm{~F} 3+5.0763 \mathrm{~F} 4-0.0005$ F5 - 5.0749 F6 + 1.3728) (18)

The un- normalized output (Current) on Hard Floor

$\mathrm{I}=0.6009 * \mathrm{I}_{\mathrm{n}}+1.2139$

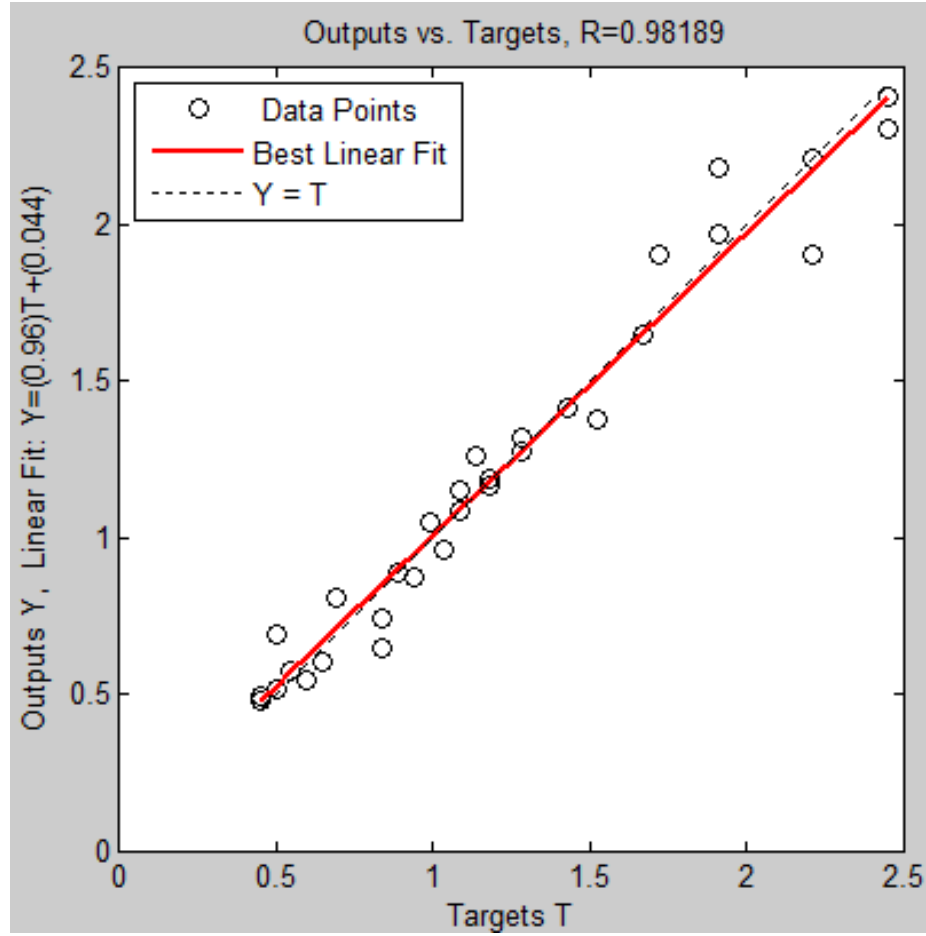

Fig. 21 Output VS Target for ANN Model testing data

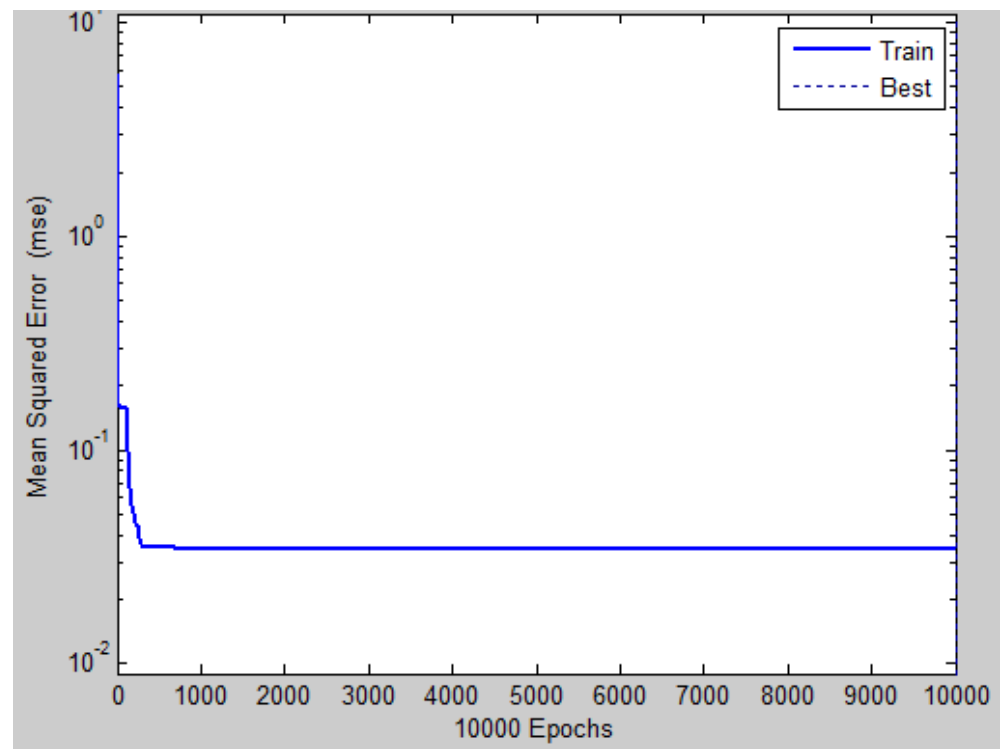

Fig. 22 Performance for the Model 


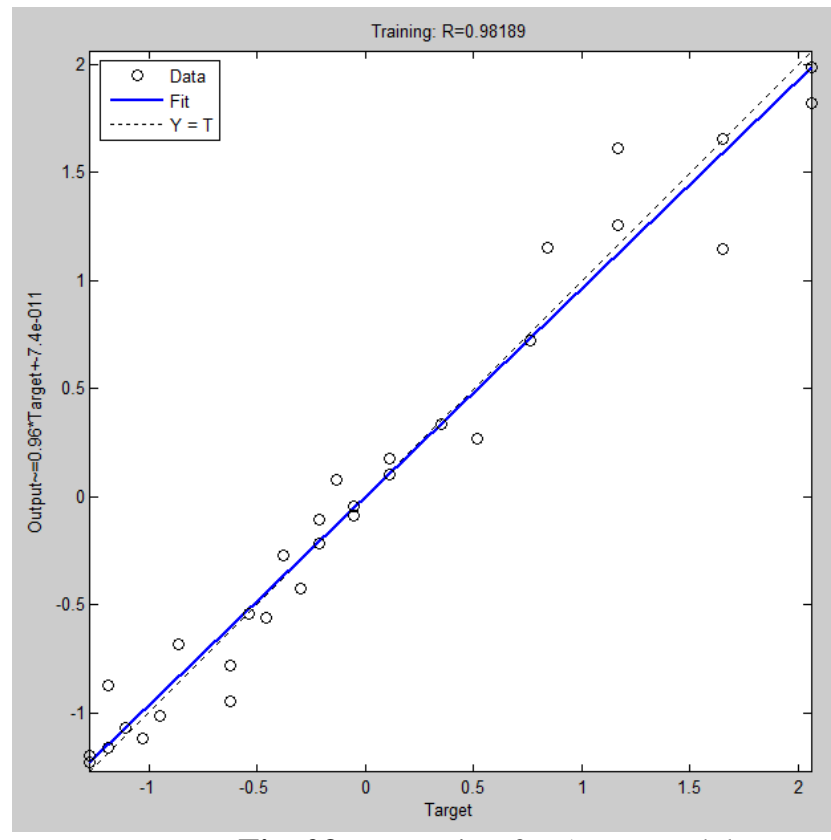

Fig. 23 Regression for ANN Model

\section{$2^{\text {nd }}$ ANN Model for the HARD FLOOR:}

Inputs: Theoretical Time, and Theoretical Velocity

Output: The Current, The Voltage ON Hard floor

Neural Network consists of two layers one hidden contains log-sigmoid function with eleven neurons and the other is the output layer contains pure-line function with two neurons.

The normalized inputs eq.n are:

Time $_{n}=($ Time -1.5000$) /(0.9092)$

Velocity $=($ Velocity -0.1070$) /(0.0649)$

Equation (20) presents the normalized input for the power and the following equations lead to the required derived equation.

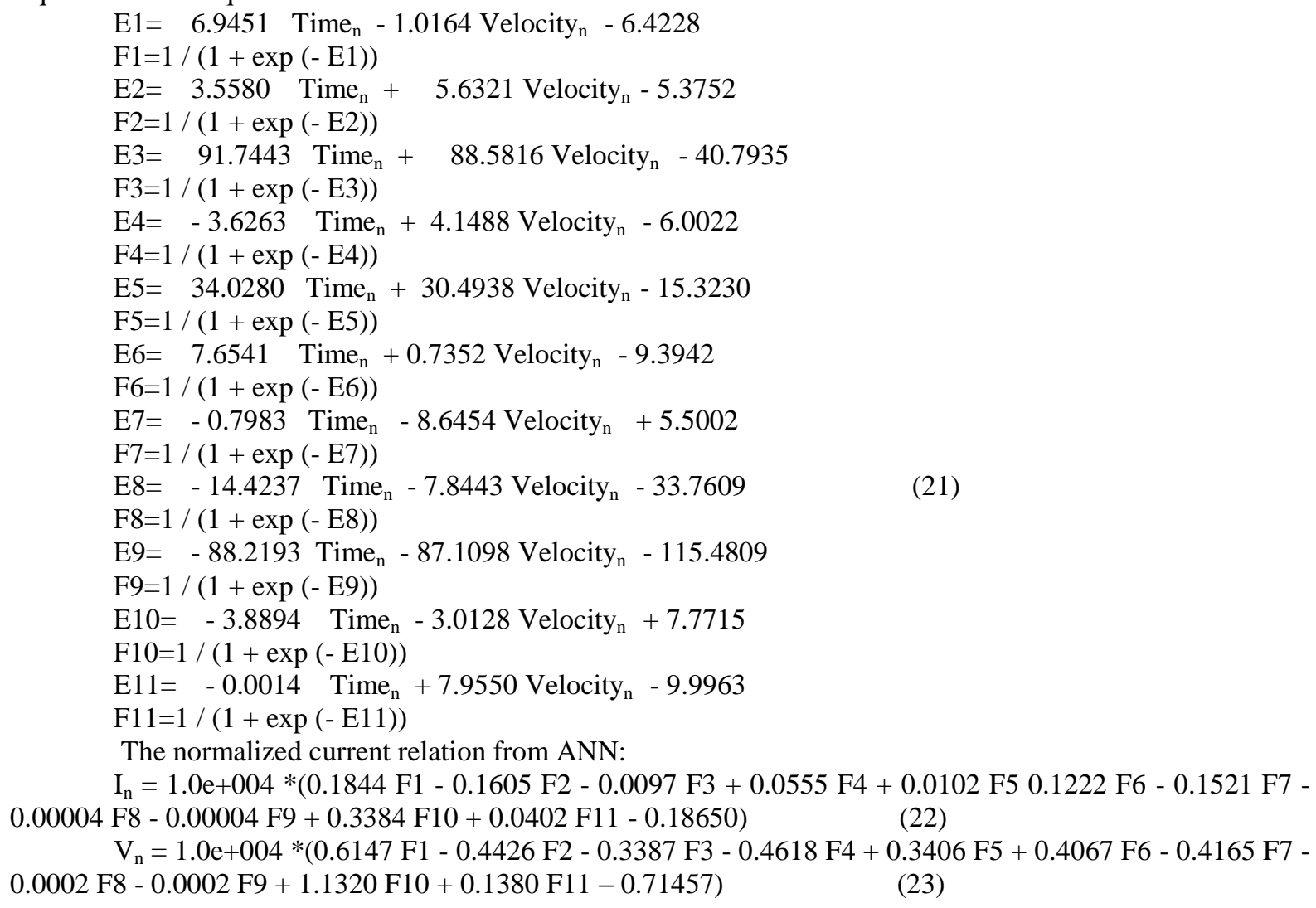$$
\mathrm{V}_{\mathrm{n}}=1.0 \mathrm{e}+004 *(0.6147 \mathrm{~F} 1-0.4426 \mathrm{~F} 2-0.3387 \mathrm{~F} 3-0.4618 \mathrm{~F} 4+0.3406 \mathrm{~F} 5+0.4067 \mathrm{~F} 6-0.4165 \mathrm{~F} 7-
$$ 
The un- normalized outputs (Current \& Voltage) for HARD FLOOR

$\mathrm{I}=0.6009 * \mathrm{I}_{\mathrm{n}}+1.2139$

$\mathrm{V}=0.0768 * \mathrm{~V}_{\mathrm{n}}+7.6241$

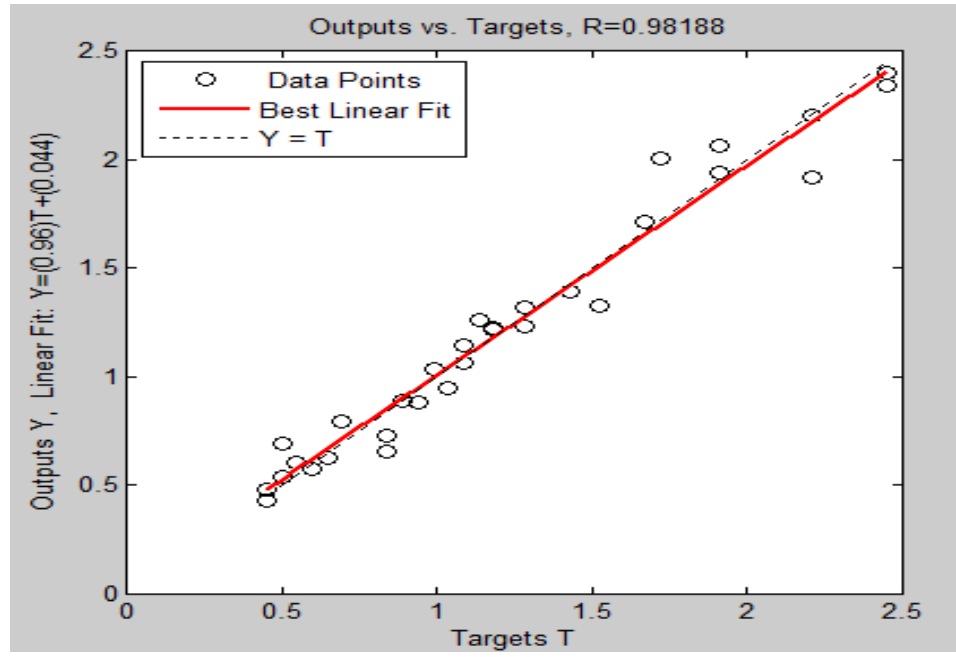

Fig. 24 Output VS Target for ANN Model testing data

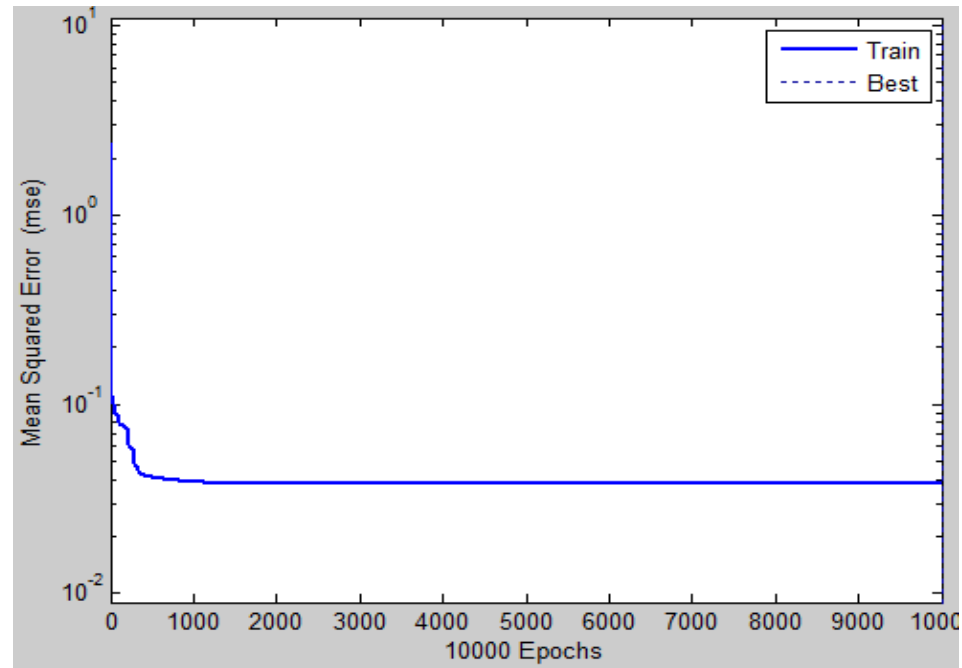

Fig. 25 Performance for the Model

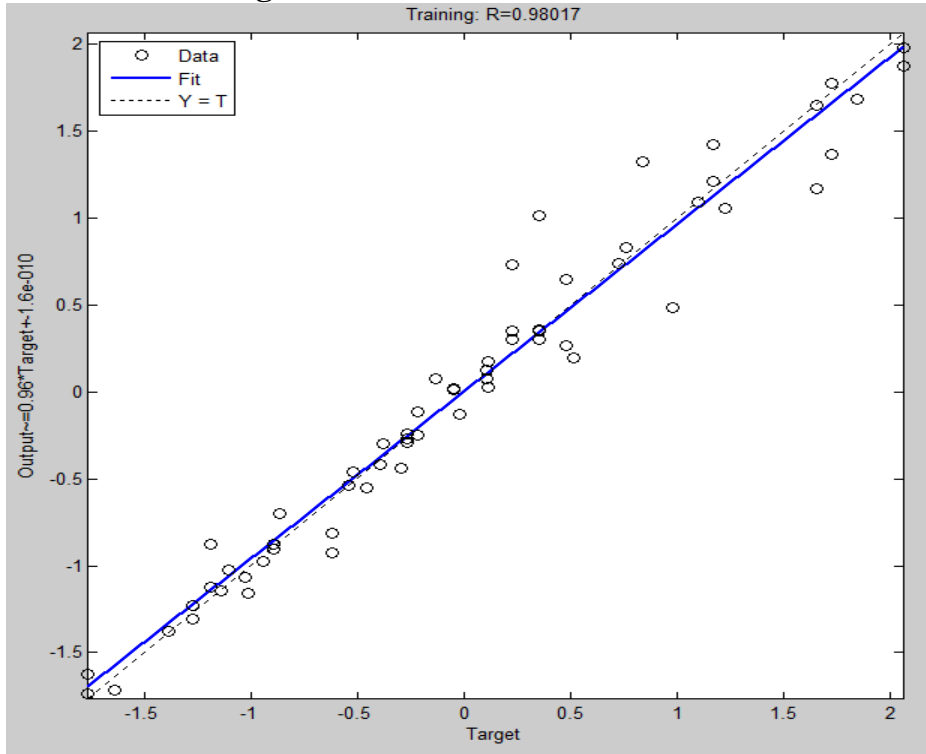

Fig. 26 Regression for ANN Model 


\section{$3^{\text {rd }}$ ANN Model for the HARD FLOOR:}

Inputs: Time, Linear Velocity, and Rotational Velocity

Output: The Current, The Voltage

Neural Network consists of two layers one hidden contains log-sigmoid function with seven neurons and the other is the output layer contains pure-line function with two neurons.

The normalized inputs eq.n are:

Time $_{n}=($ Time -1.5000$) /(0.9092)$

Linear_Velocity $\mathrm{n}_{\mathrm{n}}=($ Linear_Velocity -0.0590$) /(0.0636)$

Rotational_Velocity $_{\mathrm{n}}=($ Rotational_Velocity +0.0107$) /(0.0239)$

Equation (26) presents the normalized input for the power and the following equations lead to the required derived equation.

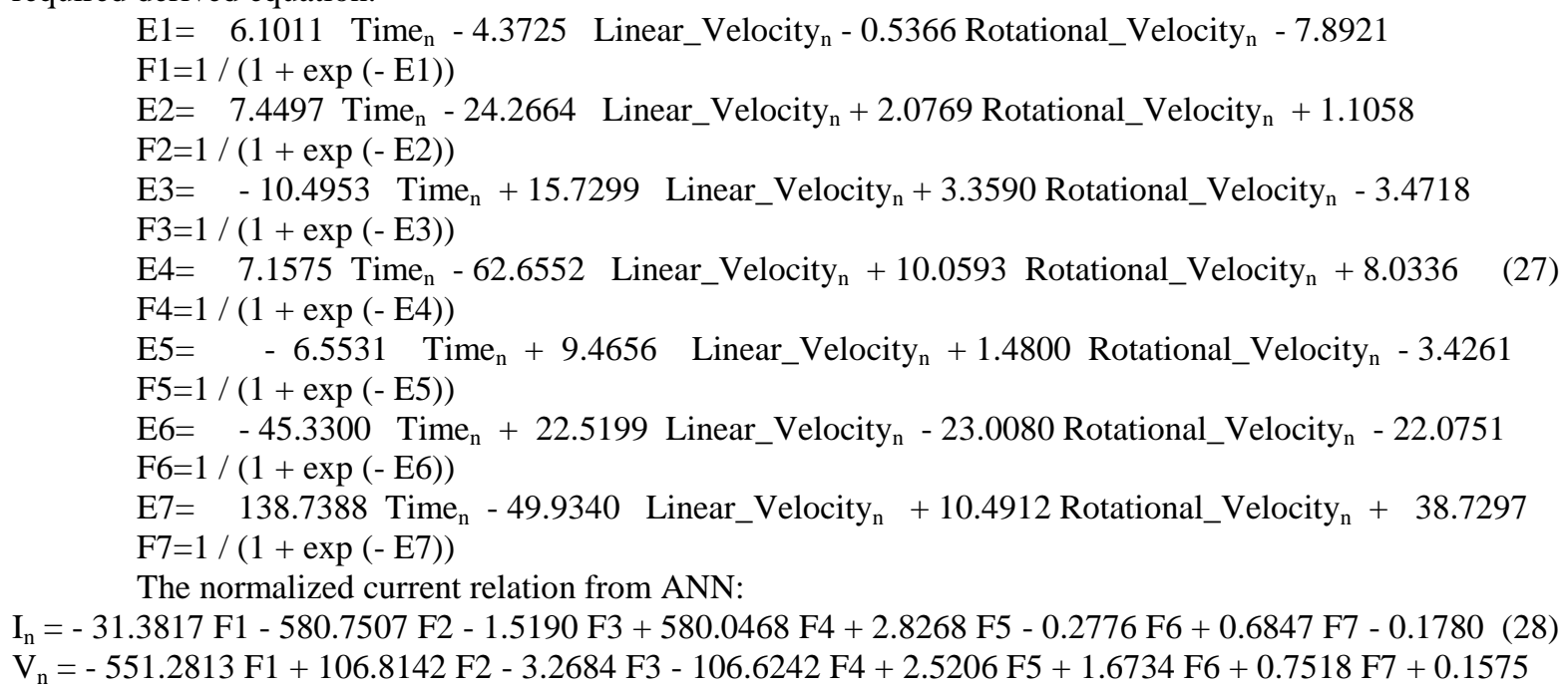

The un- normalized outputs (Current \& Voltage) for carpet

$$
\begin{aligned}
& \mathrm{I}=0.5977 * \mathrm{I}_{\mathrm{n}}+1.2486 \\
& \mathrm{~V}=0.0808 * \mathrm{~V}_{\mathrm{n}}+7.6220
\end{aligned}
$$

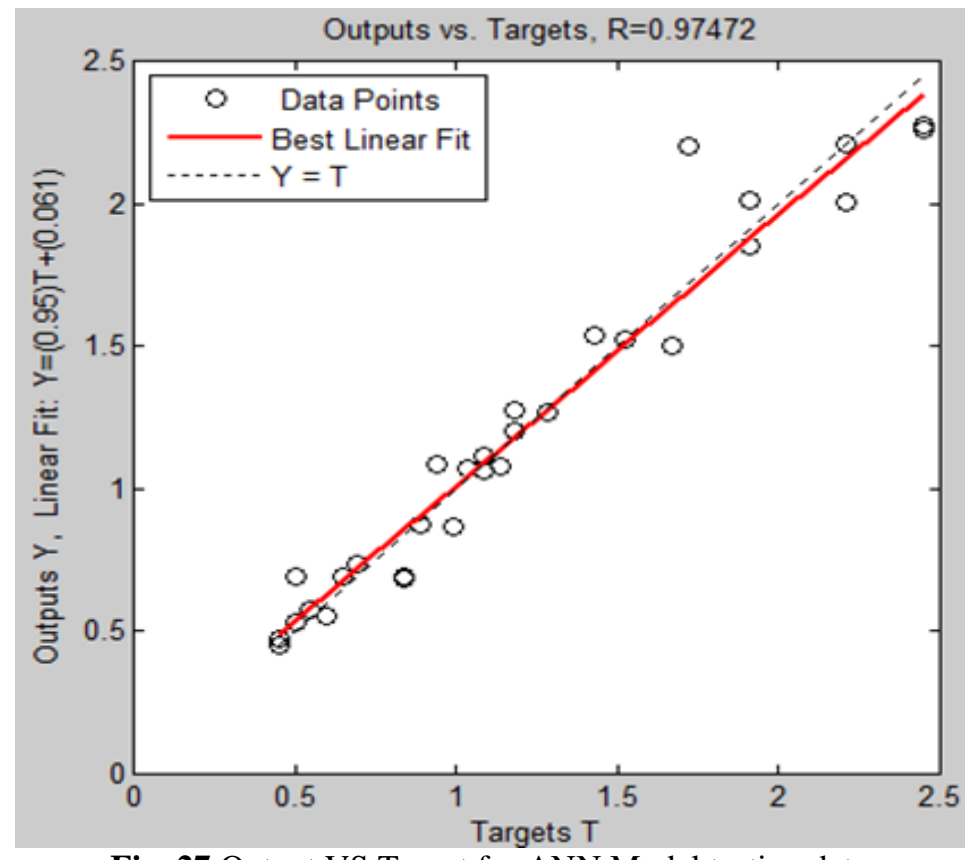

Fig. 27 Output VS Target for ANN Model testing data 


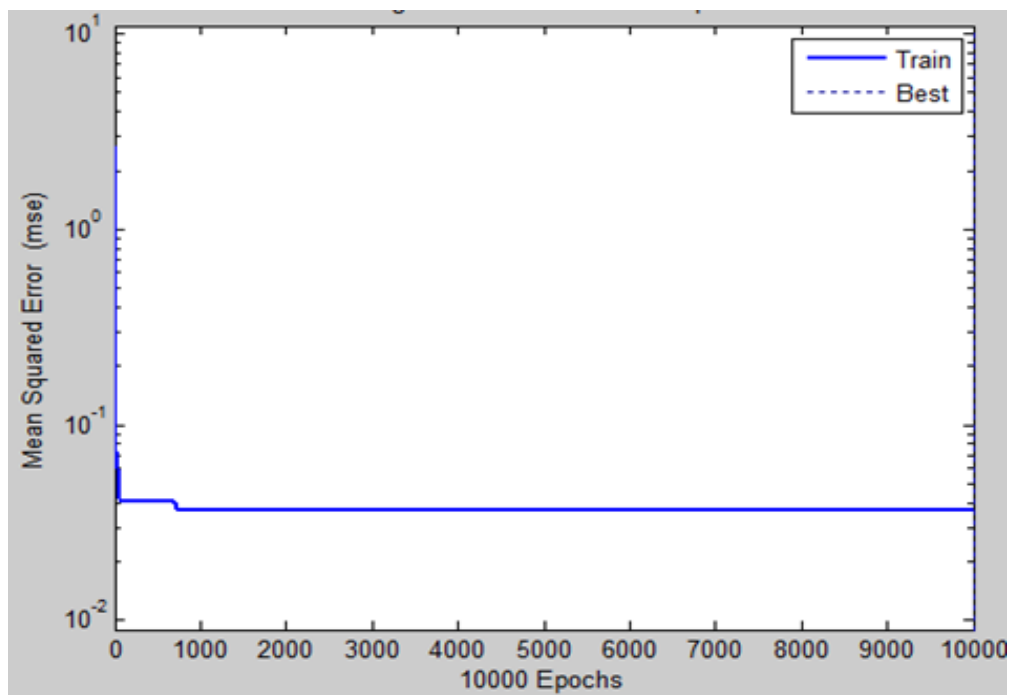

Fig. 28 Performance for the Model

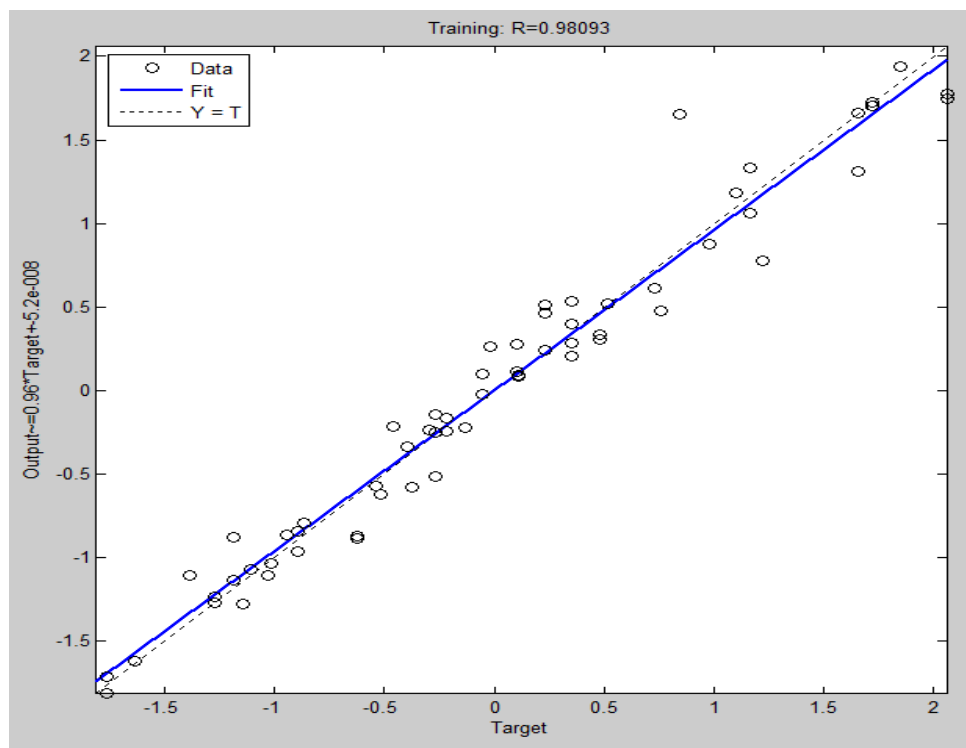

Fig. 29 Regression for ANN Model

Global model: ANN model with time and speed as inputs and current, voltage, linear speed, rotational speed on carpet, with current, voltage, linear speed, rotational speed on hard floor.

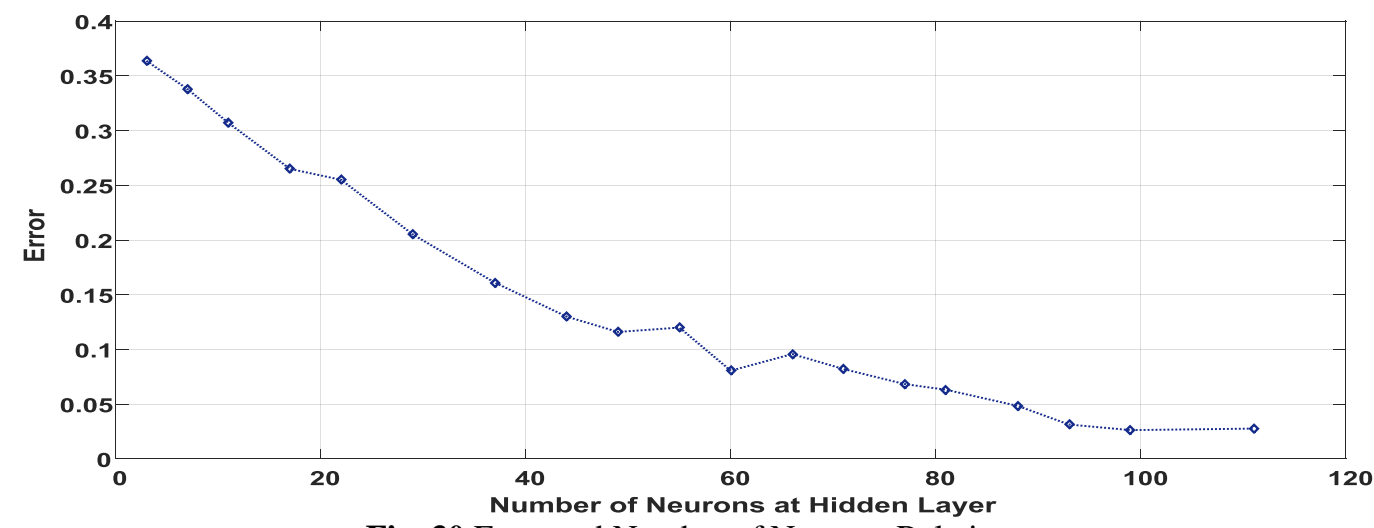

Fig. 30 Error and Number of Neurons Relation. 

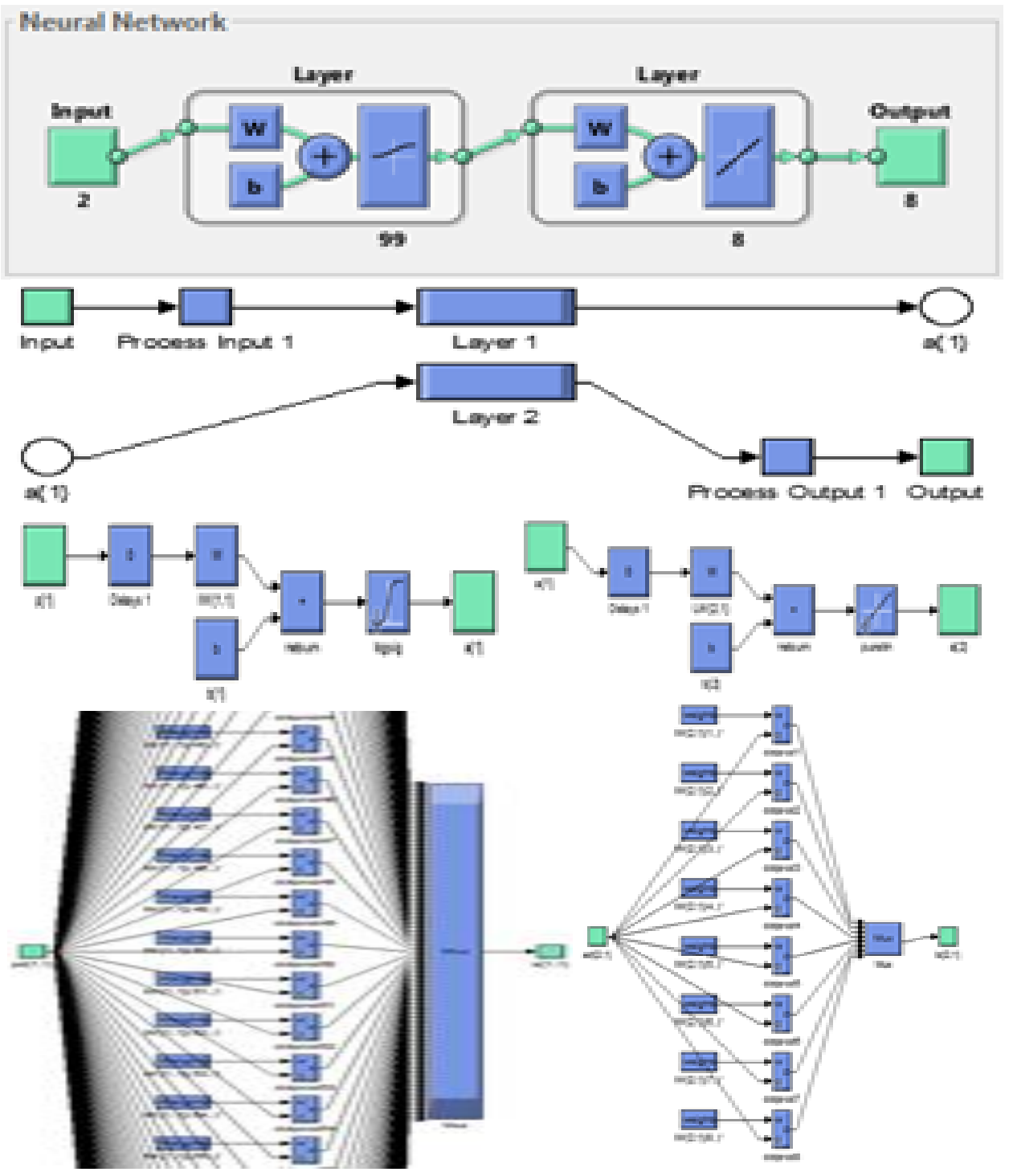

Fig. 31 Full detailed ANN Simulink Model

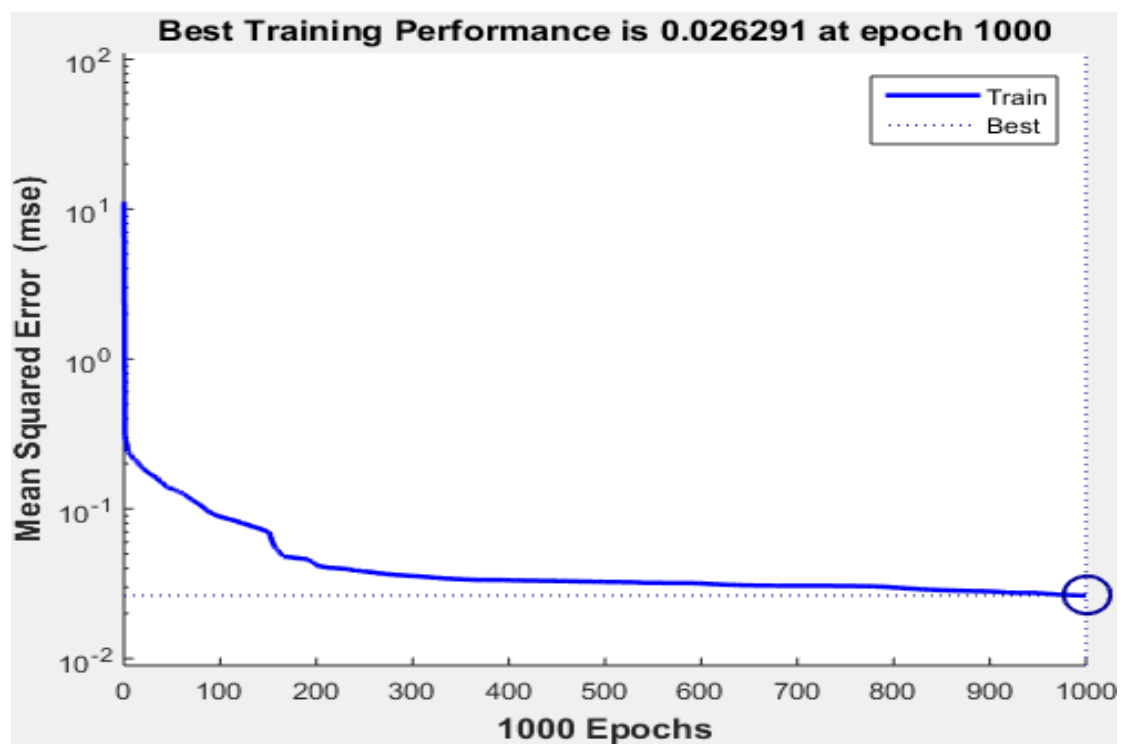

Fig. 32 ANN Model Error 


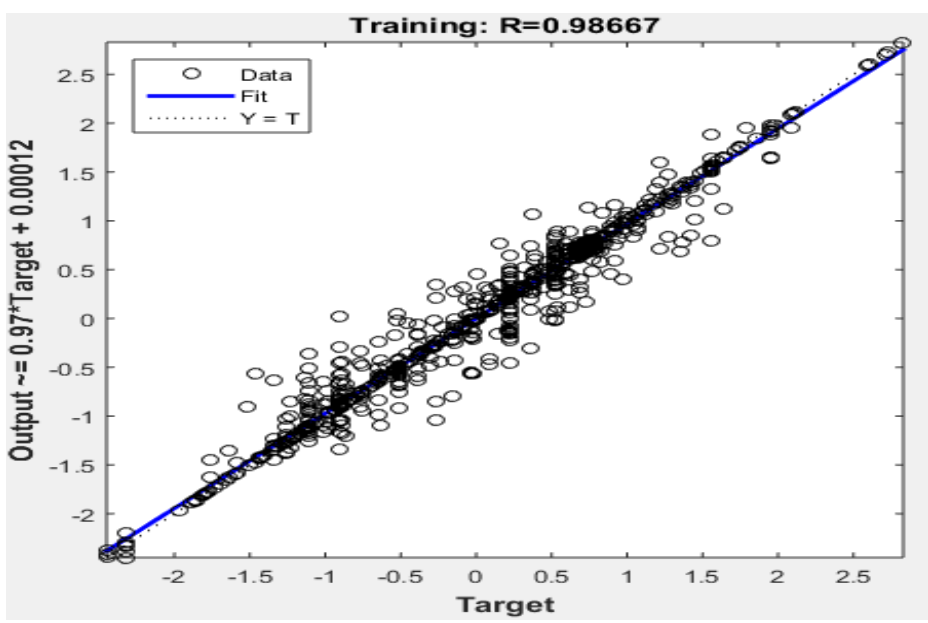

Fig. 33 ANN Model Regression Constant

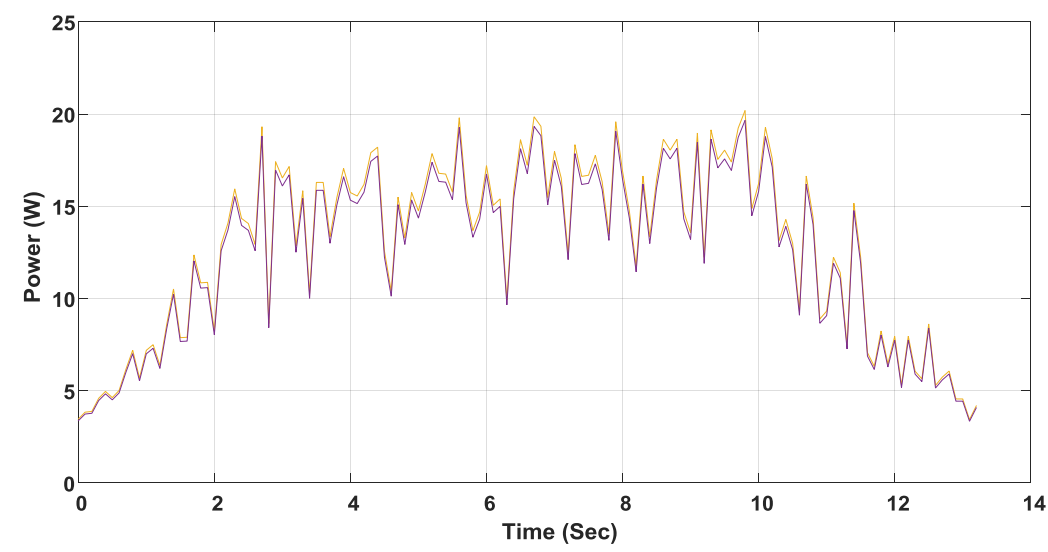

Fig. 34 ANN Model Power Comparison

\section{Conclusion}

Using the Artificial Neural Network (ANN), with feed forward back-propagation technique to introduce Robot model. This is done to use the ability of neural network for interpolation. It can predict the characteristics and performance of this mobile robot properly. The model are checked and verified by comparing actual and predicted ANN values, with good error and excellent regression factor. Finally, the algebraic equations could be deduced to use them without training the neural unit in each time or using the Simulink model to use them for optimization purposes for future work.

\section{References}

[1] M. Wahab, F. Rios-Gutierrez, A. El Shahat, "Energy Modeling of Differential Drive Robots", IEEE SoutheastCon 2015 Conference, April 9-12, 2015 in Fort Lauderdale, Florida.

[2] S. Liu and D. Sun, "Minimizing energy consumption of wheeled mobile robots via optimal motion planning," Mechatronics, IEEE/ASME Transactions on, vol. 19, no. 2, pp. 401-411, April 2014.

[3] S. Liu and D. Sun, "Modeling and experimental study for minimization of energy consumption of a mobile robot," in Advanced Intelligent Mechatronics (AIM), 2012 IEEE/ASME International Conference on, July 2012, pp. 708-713.

[4] S. Liu and D. Sun, "Optimal motion planning of a mobile robot with minimum energy consumption," in Advanced Intelligent Mechatronics (AIM), 2011 IEEE/ASME International Conference on, July 2011, pp. 43-48.

[5] S. Derammelaere, S. Dereyne, P. Defreyne, E. Algoet, F. Verbelen, and K. Stockman, "Energy efficiency measurement procedure for gearboxes in their entire operating range," in Industry Applications Society Annual Meeting, 2014 IEEE, Oct 2014, pp. 1-9.

[6] Zeyan Hu, Xiaoguang Zhou, Shimin Wei, "The modeling and controller design of an angular servo robot based on the RBF neural network adaptive control", 2014 International Conference on Advanced Mechatronic Systems (ICAMechS), 10-12 Aug. 2014, pp: $319-323$

[7] Yanbo Cui, Lei Guo, Shimin Wei, Qizheng Liao, "Design and implementation of a kind of neural networks robustness controller for variable structure bicycle robot's track-stand motion," in Information and Automation (ICIA), 2014 IEEE International Conference on , vol., no., pp.689-694, 28-30 July 2014.

[8] Adel El Shahat, "Smart Homes Systems Technology", Scholar Press Publishing, 2015.

[9] Adel El Shahat, "Artificial Neural Network (ANN): Smart \& Energy Systems Applications", Scholar Press Publishing, 2014.

[10] Adel El Shahat, "PV Module Optimum Operation Modeling", Journal of Power Technologies, Vol. 94, No 1, 2014, pp. 50-66.

[11] Adel El Shahat, Rami Haddad, Youakim Kalaani, "An Artificial Neural Network Model for Wind Energy Estimation", IEEE SoutheastCon 2015 Conference, April 9-12, 2015 in Fort Note that the journal title, volume number and issue number are set in italics. 